\title{
Japanese industry dreams of superconductor future
}

\section{- Parliament lobbied for more cash \\ - Flood of pre-emptive patents}

Tokyo

How does Japan foresee the development of high-temperature superconductors? A recent meeting between scientists and members of the House of Councillors provides some clues.

At the end of last month, four leading superconductor researchers briefed members of the special committee for science and technology of the upper house of the Diet. Ruichi Nakagawa, Director of the Science and Technology Agency's National Research Institute for Metals, began the $31 / 2$-hour session with a simple explanation of superconductivity. To convey the importance of zero resistance to the Diet members he pointed out that thermal losses due to resistance in Japan's national electricity grid equal half the electricity consumption of Tokyo, or $\$ 600,000$ million a year (more than $\$ 4,000$ million). Professor Kazuoki Fueki of Tokyo University explained resistivity at the atomic level and the notoriously complex 'BSC theory' of superconductivity, while Michihiko Nagumo of Shin Nippon Steel and Shigeru Hayakawa of Matsushita Electric Co. pointed out the potential practical applications.

The four researchers were unanimous in stressing the need for more basic research into the properties of the new materials and a theory to explain high $-T_{\mathrm{c}}$ superconductivity. They also called for international collaboration in research. The barriers to development of practical applications, such as the low critical current densities of the bulk oxides, their fragility and sensitivity to oxygen and the difficulties of processing them into wires, were emphasized. But this did not stop Hayakawa "dreaming" about the future. $\mathrm{He}$ foresees applications including gigantic liquid-crystal displays networked with superconducting wire, high-density memory devices such as centimetre-long video tapes with superconducting memory loops, supersensitive Josephson junction devices capable of monitoring the magnetic fields of the brain and heart, highspeed Josephson computers, and highdefinition satellite television.

Professor Fueki complained that lack of money is the major problem besetting basic research in the universities, a view echoed by Nakagawa, who pointed out that high-field magnets to measure magnetic-field properties of the new materials cost several hundred million yen (several million dollars) each. And the Science and
Technology Agency has recently applied for over $\mathbf{Y} 1,000$ million to build three highfield magnets at Nakagawa's institute next year (see Nature 329, 93; 1987).

On the issue of patents, there were fears that the United States may rush to develop technology and shut out Japan. Nagumo argued that the new superconductors could lead to a new industrial revolution, and that patents should not be allowed to block the way; instead there should be international "give-and-take". Hayakawa called for "open patents" that allow licensing by anyone, and he suggested that rapid development of consumer products could forestall the classification of superconductor applications as military secrets. But Sumitomo Electric Co., a cable manufacturer, is taking no chances. The company has already filed over 600 patent applications for the new superconductors

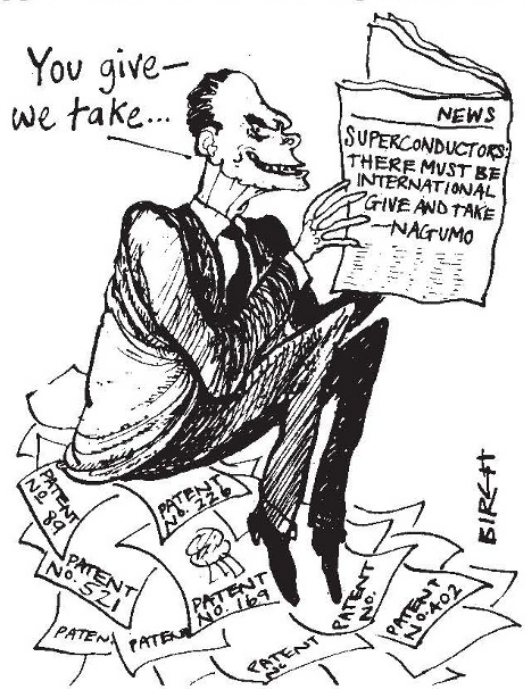

in the hope of blocking US patents and arranging cross-licensing agreements.

Japan also fears that it may prove difficult to secure adequate supplies of the raw materials to make high- $T_{c}$ superconductors. In reply to a question from house member Masao Goto, Nagumo said that Japan will need to import several million tons per year of rare earth elements such as yttrium, as opposed to the few thousand tons currently imported.

The meeting closed with a question the experts could not answer. Hiramatsu Deguchi asked about the effects of magnetic fields on people's health. Both Fueki and Nakagawa admitted that the medical effects of magnetic fields are unknown, and they called for more research into this matter.

\section{Academy pushes basics too}

\section{Washington}

US government agencies are in the midst of a debate over how best to pursue the potential of the newly discovered class of superconducting materials. The National Academy of Sciences has now weighed in with its perspective*, urging the government not to ignore the science of superconductors while it pursues their technological promise. The Academy report also cautions that interest in superconductors could place demands on the scientific and technical manpower pool beyond its capacity to respond.

The report, produced by a panel of the committee on science, engineering and public policy, says a national programme to exploit the new materials should focus on a better understanding of their essential properties, as well as the mechanism repsonsible for those properties. In addition to searching for new superconducting materials, the report suggests starting the process of creating prototype devices that might incorporate the new materials. For the next fiscal year, the panel reckons that $\$ 100$ million will provide "a good beginning" in exploring superconducting compounds and their potential uses.

The rallying cry of improving economic competitiveness has frequently been sounded to justify research on superconductivity. Both Congress and the Reagan administration are anxious that research advances be translated into commercial products in a timely fashion. But the Academy report points out that the world superconductivity market is relatively small, although products made with superconductors - especially medical imaging devices - represent a much larger market. Given the engineering problems presented by the ceramic superconducting materials, the panel expects it will take a decade of precommercial exploration to establish the range of potential applications. Although the panel is unanimous that the new materials are bound to result in new economic growth, it will take room-temperature superconductivity to bring about a revolution.

The attraction of working with superconductors, both because of the intellectual excitement they have generated and the financial backing they are likely to attract, may syphon off engineers from other research areas where they cannot easily be replaced. The report urges that attention be paid to the educational demands that must be met if adequate numbers of suitably trained people are to continue to enter the field. Joseph Palca

${ }^{*}$ High-Temperature Superconductivity, Committee on Science, Engineering, and Public Policy, National Academy of Sciences, Washington, D.C. 